\title{
Introduction to the special issue on Gun violence: addressing a critical public health challenge
}

\author{
Alan J. Christensen ${ }^{1} \cdot$ Rebecca Cunningham ${ }^{2} \cdot$ Alan Delamater $^{3} \cdot$ Nancy Hamilton $^{4}$
}

Published online: August 1, 2019

(C) Springer Science+Business Media, LLC, part of Springer Nature 2019

Nearly 40,000 lives are lost in gun-related deaths in the United States each year with another approximately 70,000 American sustaining gun related injuries https://www.cdc. gov/nchs/fastats/injury.htm; Weinberger et al. (2015). Whether the result of unintentional injuries, homicides, or suicides, firearm-related morbidity and mortality has long posed a substantial risk to public health and safety in the United States. Unfortunately, research funding in this area has lagged far behind funding directed toward understanding other forms of injury or illness substantially limiting the ability of health professionals, law enforcement officials, or policy makers to effectively address the issue (Stark \& Shah, 2017). Moreover, gun-related violence has itself only recently begun to be characterized as a public health issue, a fact that seems inexplicable given the long standing societal impact of the issue (Bauchner et al., 2017). In recent years, a string of tragic, high profile mass shootings, particularly those involving school children, have seemed to bring about some shift in public sentiment toward a greater sense of urgency for addressing the scourge of gun violence. However, because of past constraints on conducting or funding gun violence related research at the federal level (Stark \& Shah, 2017), the knowledge base for determining what approach is likely to

\footnotetext{
Alan J. Christensen

Christensenal19@ecu.edu

1 Department of Psychology, East Carolina University, Greenville, NC, USA

2 University of Michigan, Ann Arbor, MI, USA

3 University of Miami, Coral Gables, FL, USA

4 University of Kansas, Lawrence, KS, USA
}

be most useful from a public health, law enforcement, or policy perspective, remains elusive.

As public health scientists we believe that efforts to address gun violence should be based on scientific evidence. Just as policy changes associated with automotive safety, other preventive health recommendations, workplace safety, and air travel, have largely evolved from an empirical evidence base, so should policy changes or other measures developed to decrease the public health toll of gun violence. Unfortunately, while reports of gun violence have become part of the daily fabric of our society, development of an evidence base to help guide efforts around gun violence prevention has until recently failed to be a priority for the scientific community, demanded by the public, or supported by funders.

The current Journal of Behavioral Medicine special issue constitutes an early step toward organizing, synthesizing, and communicating the current "state of the evidence" regarding gun violence research. The diverse set of papers address the wide range of individual level, community level, and policy factors associated with risk for gun violence and the morbidity and mortality associated with firearm-related injuries. The 11 empirical papers comprising this issue span a range of related topics including several studies examining the effects of gun violence and risk factors for gun violence among children and adolescents. Papers by Abaya et al. (2019), Goldstick et al. (2019), and Schnitzer et al. (2019) each examine factors related to firearm access and firearm-related assaults in at-risk adolescents including delineating associated behavioral risk factors such as drug use, past violence victimization, and suicidality. Jager-Hyman et al. (2019) address the feasibility and acceptability of firearm ownership screening and firearm safety counseling in 
pediatric primary care. Rajan et al. (2019) argues that youth gun violence exposure has deleterious effects on children comparable to other adverse childhood experiences and should be classified accordingly.

Other articles address issues related to gun violence in adults. Lyons et al. (2019) examines how being an adult victim of a firearm injury leads to behavior changes that may further increase the likelihood of a subsequent firearm injury. Pizarro et al. (2019) uses a mixed methods approach to better understand details of the transactions or events that immediately precede or escalate into firearm homicides, while Small et al. (2019) examines how law enforcement decisions to remove firearms during a domestic violence incident are associated with subsequent intimate partner violence reports. Environmental factors such as neighborhood blight and vacant building demolitions are also examined as potential risk factors for firearm violence (Jay et al., 2019). Other contributions examine the importance of methodologic tools utilizing multiple independent data sources (e.g., "capture-recapture methods") and Center for Disease Control National reporting systems that are essential to accurately understanding the extent and the context of gun related injuries (Post et al., 2019; Schwab-Reese \& Peek-Asa, 2019). In addition to these empirical contributions, the five systematic review papers contributed by the Firearm safety Among Children and Teens (FACTS) consortium group synthesize the state of our current knowledge involving gun violence in children and are described and presented later in this issue (Cunningham et al., 2019).

Each of the authors that has contributed articles to this special issue is a pioneer, working in an area that has for too long been understudied and underfunded. We applaud the efforts of each of the investigative teams, as well as the institutions, professional societies, and funding sources that have supported their research. It is important to emphasize that the work herein constitutes scientific inquiry and evidence, not tied to a particular policy agenda or political ideology. Indeed the findings and recommendations of the compiled work do not fit neatly into any given ideological position. Above all else, the take-home message of the collected work is that gun violence has the potential to be understood much the same way as many other public health threats have been understood, through systematic scientific inquiry that utilizes the best available scientific methods adopted from a range of public health disciplines. While much more work is clearly necessary, a better understanding into the individual, sociocultural, environmental, and policy factors that influence firearm violence risk seems within reach. Our hope is that scientific evidence can begin to serve as the foundation for the national conversation on gun violence and appropriate policies to better promote public health.

\section{Compliance with ethical standards}

Human and animal rights and Informed consent All procedures followed were in accordance with ethical standards of the responsible committee on human experimentation (institutional and national) and with the Helsinki Declaration of 1975, as revised in 2000. Informed consent was obtained from all patients for being included in the study.

\section{References}

Abaya, R., Atte, T., Herres, J., Diamond, G., \& Fein, J. A. (2019). Characteristics and behavioral risk factors of firearm-exposed youth in an urban emergency department. Journal of Behavioral Medicine. https://doi.org/10.1007/s10865-019-00054-z.

Bauchner, H., Rivara, F. P., Bonow, R. O., Bressler, N. M., Disis, M. L., Heckers, S., et al. (2017). Death by gun violence-A public health crisis. JAMA, 318, 1763-1764. https://doi.org/10.1001/ jama.2017.16446

Center for Disease Control and Prevention. National Center for Health Statistics. https://www.cdc.gov/nchs/fastats/injury.htm. Accessed May 14, 2019.

Cunningham, R., Carter, P., \& Zimmerman, M. (2019). The Firearm Safety Among Children and Teens (FACTS) consortium: Defining the current state of the science on pediatric firearm injury prevention. Journal of Behavioral Medicine. https://doi. org/10.1007/s10865-019-00035-2.

Goldstick, J., Carter, P., Heinze, J., Walton, M., Zimmerman, M., \& Cunningham, R. (2019). Predictors of transitions in firearm assault behavior among drug-using youth presenting to an urban emergency department. Journal of Behavioral Medicine. https:// doi.org/10.1007/s10865-019-00021-8.

Jaeger-Hyman, S., Benjamin Wolk, C., Ahmedani, B. K., Zeber, J. E., Fein, J. A., Brown, G. K., et al. (2019). Perspectives from firearm stakeholders on firearm safety promotion in pediatric primary care as a suicide prevention strategy: A qualitative study. Journal of Behavioral Medicine. https://doi.org/10.1007/s10865019-00074-9.

Jay, J., Miratix, L. W., Branas, C. C., Zimmerman, M. A., \& Hemenway, D. (2019). Urban building demolitions, firearm violence and drug crime. Journal of Behavioral Medicine. https://doi.org/10.1007/s10865-019-00031-6.

Lyons, V. H., Rivara, F. P., Ning-Xue Yan, A., Currier, C., Ballsmith, B., Haggerty, K. P., et al. (2019). Firearm-related behaviors following firearm injury: Changes in ownership, carrying and storage. Journal of Behavioral Medicine. https://doi.org/10. 1007/s10865-019-00052-1.

Pizarro, J. M., Holt, K., \& Pelletier, K. R. (2019). An examination of the situated transactions of firearm homicides. Journal of Behavioral Medicine. https://doi.org/10.1007/s10865-01900050-3.

Post, L. A., Belsan, Z., Spano, R., \& Vaca, F. (2019). Bolstering gun injury surveillance accuracy using capture-recapture methods. Journal of Behavioral Medicine. https://doi.org/10.1007/s10865019-00017-4.

Rajan, S., Branas, C. C., Myers, D., \& Agrawal, N. (2019). Youth exposure to violence involving a gun: evidence for adverse childhood experience classification. Journal of Behavioral Medicine. https://doi.org/10.1007/s10865-019-00053-0.

Schnitzer, P. G., Dykstra, H. K., Trigyldias, T. A., \& Lichenstein, R. (2019). Firearm suicide among youth in the United States, 2004-2015. Journal of Behavioral Medicine. https://doi.org/10. 1007/s10865-019-00037-0.

Schwab-Reese, L. M., \& Peek-Asa, C. (2019). Factors contributing to homicide-suicide: Differences between firearm and non-firearm 
deaths. Journal of Behavioral Medicine. https://doi.org/10.1007/ s10865-019-00066-9.

Small, D. S., Sorenson, S. B., \& Berk, R. A. (2019). After the gun: Examining police visits and intimate partner violence following incidents involving a firearm. Journal of Behavioral Medicine. https://doi.org/10.1007/s10865-019-00013-8.

Stark, D. E., \& Shah, N. H. (2017). Funding and publication of research on gun violence and other leading causes of death. JAMA, 317, 84-85. https://doi.org/10.1001/jama.2016.16215

Weinberger, S. E., Hoyt, D. B., Lawrence, H. C., Levin, S., Henley, D. E., Alden, E. R., et al. (2015). Firearm-related injury and death in the United States: A call to action from 8 health professional organizations and the American Bar Association. Annals of Internal Medicine, 162, 513-516. https://doi.org/10. 7326/M15-0337

Publisher's Note Springer Nature remains neutral with regard to jurisdictional claims in published maps and institutional affiliations. 